\title{
IOT MODEL FOR SMART UNIVERSITIES: ARCHiteCture, CHALlENGES, AND APPLICATIONS
}

\author{
Amr Adel \\ Department of Technology \& Innovation, Whitecliffe College \\ of Technology and Innovation, Auckland, New Zealand
}

\begin{abstract}
The utilization and implementation of IoT based technology in the learning environment is effective as all the activities among everyone is related to technology only. Also the adoption of the use of the technology is preferred by many. Hence, proposing a model that can regulate the various process of institution is essential as well as advantageous for the instructors as well as to the learners. Hence, the various aspect that comes up in adopting such a model is briefly described along with the flow that the model will exercise. The benefits, challenges and its application in the field of education is represented well. The researchers can further expand the study and refine as well as carry out future research in this domain.
\end{abstract}

\section{KEYWORDS}

Internet of Things, Higher Education, E-Learning, Radio-frequency identification, Learning Environment \& Learner.

\section{INTRODUCTION}

The advancement of technology in the twenty first century has accelerated the development of technologies as well as the innovations in the same field. Technology have elated several industries starting from construction, healthcare, food as well as the field of education. The effective application of the technologies is helping the students as well as the instructor to ease the process of learning. The concept of e-learning and smart class are the new picture of the modern world. The devices that runs on the concept of IoT are the prime provider of advantages in the learning process. The sensors and RFID tags are the basis of these technologies.

Therefore, the discussion is about the adoption of IoT based model in higher education. This will be started with the evidences of the earlier implementation of the same. The architecture of the proposed model is discussed leading to the flow of the operations of the proposed model, then the analytics that coursed in the learning process, followed by the benefits that the model can provide to all the stakeholders considered in the model along with the challenges they may face while adopting the same. Lastly, the application of the model in the education system is discussed in brief.

\section{RELATED WORK}

According to Sarnok \& Wannapiroon, (2018), leaning is connected to the development of the personality of the humans. Hence the ways in which the learning process is carried out is also

Dhinaharan Nagamalai et al. (Eds): CSEIT, WiMoNe, NCS, CIoT, CMLA, DMSE, NLPD - 2020

pp. 121-130, 2020. CS \& IT - CSCP 2020

DOI: $10.5121 /$ csit.2020.101111 
essential to regulate with the changing world and economy. The author has discussed about the opinion of the psychologist that the process of learning is never ending hence, evolving the process with the developed technologies are a must [29]. The journey of learning has the aim to provide "transformative learning" with the developing skills that are required to be a successful person in that very field. The learning in the twenty first century is expected to change and the new set of skills must be introduced. The new process that are quoted by the author are learning that is problem-based, effective interaction, connectivism, learning that is project-based, content delivery through the use of latest technology and constructivism [11]. In today's world the management of education has different perspective of the classroom that the earlier one. This has been observed in the higher education mostly. The student of different age group and generations are coming in one classroom for learning [25]. It has been observed that the learning process enhance in doing do and sharing of knowledge has been effective for all the participant's candidates in the room. The internet of everything is referred to the devices that are connected via the internet. The RFID are considered to be the new era helpers of humans. The new and advanced technologies do not only are present in the equipment of home appliances like TV, remote or cars, but also in the field of education. The instructors of education are expected to get familiar with the technical and functional based teaching instruments [30]. Therefore, it will enable the instructors to stimulate the learning process for the new generation students. The use of the devices needed the proper environment in which the students can perform the activities on the digital devices. The perception of connective learning can also be fulfilled through the digital devices irrespective of the place of learning. The authors have provided a framework for connectivism learning with the aid of IOT. The development of smart classroom is formed by the internet of things and the system consist of three parts those are cameras those are IoT based, those will capture the activities taking place inside the classroom to keep track of the environment, safety, etc. [26]. The next on is the system of smart check, it will have the devices like sensors and tags to monitor the activities of the instructors and the students and provide analysis for betterment. The last one is the office system that is IoT based to develop the devices used by the learners in performing better with the new age technology with controlled budget and more usability out of them [19].

As per Miraz et al., 2015, the usability of Internet of things have accelerated in several fields and the field of literature is not away from this too. The future is expected to have the utilization of the technologies at greater levels and new versions of Internet of everything [5]. The benefits that are stated by the use of this technology is that the co0nnecting with every possible object in the world with the possibility of shared knowledge and intelligence [19]. As the acceleration of urbanization flourishes the implementation of the IoT based devices are becoming critical. The elearning is also developed by the implementation of IoT based devices, I provide easy access of learning materials for the students. It allows monitoring of the students for keeping track of the progress in the education field and giving effective feedback.

The benefits of cloud computing are concrete with for exploring the IoT based leaning. The presence of clod computing is helping in overcoming the difficulties of new age technologies in terms of storing and data accessing purposes. It eases the ability to store information related to education filed infinitely [3]. The services of cloud are well utilized by the students or learners so as to collaborate with other learners irrespective of the location and time zone [22]. The information accessed by the IoT devices are stored in the cloud and hence makes the accessibility easy. One of the feature of cloud is to provide interconnectivity of the devices and information. This allows the learners to collaborate and learn conveniently and effectively. The requirement of physical classroom is also solved by the present of cloud computing, as the teachers can easy conduct online based formal class with the operations of cloud services. 


\section{Architecture of Proposed Model}

The educational model that is developed for the purpose of adopting the IoT based model in the higher education in New Zealand is consist of several participating department of the university, those are collected to other several divisions. The concept of IoT is primarily based on the use of sensors and tags. These devices collect all the activities and events occurring in the university, All the participating entities that are present in the proposed model such as; students, teachers, management department, library, parents, laboratory, gymnasium, classroom, staff, canteen, restroom, auditorium and the Main gates of the university are all equipped with sensors and tags. The basic work of the sensors is to capture the activities around, those activities may be in any form such as physical, electrical or chemical and then convert them to electrical signals. Those signals will be stored in the cloud of the university as a set of information of one entity of the model. Therefore, in our model the entities will be surrounded by the sensors either in the room they are working or in the form of wearable devices. Then all the information captured are transferred through three possible stages and then the timer regulates the timing of the information pass and finally store in the cloud where the analysis of the data and information are performed and revert back whenever needed by the authority of the university. As the data generated by the devices are obtained in huge quantity the implementation of the concept of Big data is also valuable to manage the inventory activities and make the education process more effective, attractive and interesting experience for the students. The model (Fig.1) will work on single server and the network bandwidth for the transmission of data will be wide enough to regulate all the activities smoothly.

\subsection{The Proposed Model}

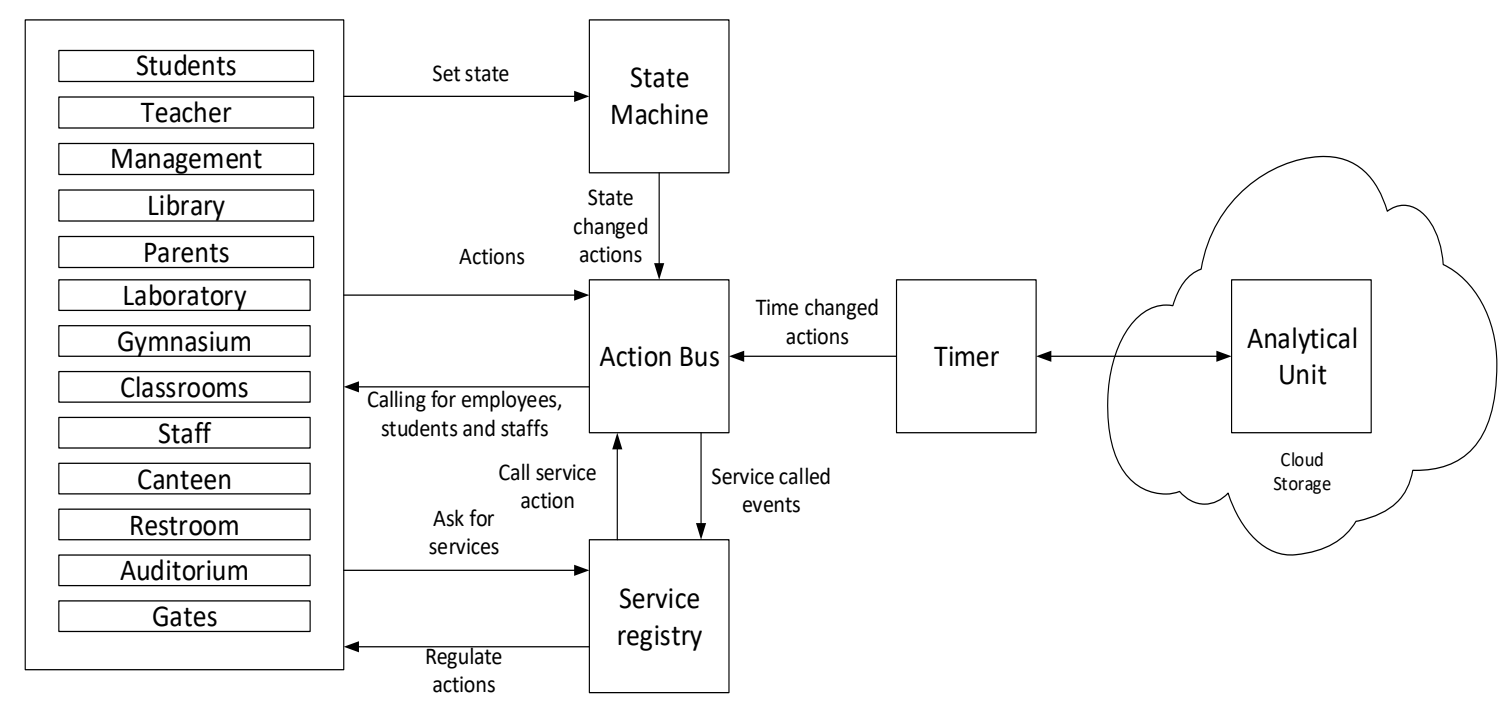

Figure 1. Educational Model IoT-based

The sensors associated with the participating entities in the proposed model have the basic functionality of gathering data and transfer them with encrypted protection to the other department as represented in the model. Whenever a sensor captures a set of information the state machine changes the state of that sensor to show that it has performed its work. Then the action bus helps in managing the data with the help of the APIs. Then the service registry provides the requested services of the different information collected through the API query. The data that is 
collected in the huge quantity are first rectifies for its credibility and then sent for the further operations. The data are translated into understandable form and analysed by the analytics of Machine Learning [1]. The flow of data into the proposed model is doe in the possible manner; firstly, the data in captured through the sensors present in the surrounding as well as through the wearable present to the staffs, students, and the instructors. Then the generated data is collected to analyse the credibility of the sources it got captured so that the huge amount of data can be minimized, and further analysis process of the data will take lesser time too. The next phase is the setting the status of the operation, when one operation is completed that is associated with the set machine and the status of the operations set to be completed or incomplete[14]. Furthermore, the operation that are assigned as the state changed are further goes to the Action bus, the stakeholders can ask for the actions that is obtained from the earlier generated and analysed data. Similarly, the action bus also calls for the stakeholder to capture the data directly. Next the service registry is present to regulate the actions of the stakeholders of the system on the basis of the data generate and captured. The actions are called, and service are reverted back to the action bus. The timer sets the fixed time of the data to be entered into the cloud storage and retrieval time [15]. Hence maintaining the proper translation of the data from the stakeholders and back to the system. Then the last step of the system is to store the data in the cloud store with the presence of infinite space and the retrieval of the data and information in need by the stakeholders. Hence the overall system is quite complicated yet simple in the flow of the information to extract the important data and use them for the betterment of the institute in the long run.

\subsection{Analytics of the Learning Process}

The analytics of learning are the basis of gathering, analysis and distribute information and data of the learners in their own environment. This analytical process occurs to optimize the opportunities it provides further. The proposed system is powered by the Machine learning concept for the smart work optimization. As the ability of the human brain is to keep the shortterm memory and long term memory the system also keeps all the data generated in the form of usable data and memory in the system [32]. The learning analytics are present to provide shape to the data obtained. The analytical approach that is commonly used to find the patterns in the data collected by the sensors or the tags are by the structural approach of machine learning [7]. Also, the data mining, factor analysis are other helpful ways in which the analytics are cleared at effective manner. The ability to predict from the obtained data is required to provide manifestation to the proposed model [10]. The already existing data in the system will be used to compare with the new data and predict for the future with the aids of tolls and technologies of the machine learning theories.

All the components of a particular classroom will be connected to a single node and thus the sensors and other devices to collect data can run smoothly on them. From the wearable devices and the standalone physical devices installed in the classrooms will capture the activities of the students and process them in the model as discussed above [20]. Then the probable output will be obtained to have suggestion, improvements about the environment of the student, their learning abilities, and several other aspects that the instructors can work on and make changes as required.

\subsection{Benefits of the Model}

The benefits that the proposed model will bring into the higher education of New Zealand are by the emerging technologies that facilitates the smooth operations of the participating entities. The technological innovation in the twenty first century has bought revolution in the field of education. The ability to provide a cohesive and collaborative approach by the staffs and the 
student $t$ under one roof is beneficial for provide the new age of knowledge [4]. The benefits the model is expected to reflect for the higher education are as follows:

\subsubsection{Improved Results of Classroom}

The IoT based classroom and overall system of the higher education will allow to acquire more knowledge of all the student around and their capabilities and abilities in terms of performance in the classroom. Those statistics can be analysed well to gain the positivity in the activities and try to explore them and the downsides to be improved in the future.

\subsubsection{Enhance the Skills of Critical Thinking}

The use of the devised for conducting the learning process will be equipped with the sensors and the tags hence the smart features will enable the learners as well as the instructors to enhance their skills from the previous track records [27].

\subsubsection{Introduction of New Techniques of Solving Problems}

The present of new technologies and innovative ways to learn like through the projectors, understand scenarios in the three dimensions, this will enhance the analytical skills of the learners.

\subsubsection{Increased Interaction of the Learners}

The devices will encourage in collaborative learning as well as enable the learners to interact more with the devices and the co-learners. The interaction with the instructors will not be only limited to the classrooms, even the laptops and the mobile phones will be able to access the lecture sessions.

\subsubsection{Online Library}

The books from the libraries will be available in the cloud storage of the education centre. Then the traditional ways of issuing of books will be avoided this was time taking. The availability of the online books will be made available to the students [9]. The students will be given a period of subscription to access the book from the cloud through their mobile devices. The sensors will provide notification of the return date of the book that means subscription will be closed for the particular book. In this way the shift from the paperback to the online based will formulate minimizing the use of paper as a whole.

\subsubsection{Personalizing lectures}

As the sensors will be able to gather data about each student in the classrooms, then providing personalized lecture sessions will be possible. This will enable the student to have better understanding of their week point in learning and help them in scoring better.

\subsubsection{Authorised Access into System of Institute}

when the system will be fully equipped with the technologically advanced devices such as the sensors and other IoT device. All the operations occurring across the institute will be tracked and monitored for the unauthorised access [24]. The proper screening will enable the management to perform regulatory process on the basis of the obtained data [12]. The entry and exist gates can 
be monitored better. The information system devices will have more security as the continuous monitoring will be followed automatically.

\subsubsection{Better health of the stakeholders}

The devices containing the sensors and RFID tags available to the stakeholders in the form of wearable or physical devices attached at the different departments of the institute will collect all the habits of the members and keep track of the food habits and hygiene [13]. This will allow the management to give update about the health of the members and keep them up-to-date with their health condition. The aim is to reduce the sick possibilities in the institute and maintain healthy participant inside the campus. This will keep the records of the institute at the higher places.

\subsection{Challenges $\&$ Limitations in adopting the model}

The difficulties that may occur at the time of adopting the IoT based education by the stakeholders are as follows:

\subsubsection{Installation Cost}

The overall model of the proposed system consists of high cost technologies and hence the arranging all the components together will include a huge amount of money [6]. Hence the installing the overall model together can cause the investment of a huge amount of money of the institute. Also the competition is high for adopting technology based system in every field and especially in the field of education.

\subsubsection{Lack of knowledge}

The authorities present in the institute such as the staffs, instructors and students may not have all the proper knowledge about the devices and the technologies used in the system [31]. Hence the adoption of all the operations of the system may take a longer period of time, this may reduce the progress of the institute. All the people in the institute may not have the complete knowledge of the operations across the model.

\subsubsection{Security Concerns}

As the model is based on the emerging technologies; hence the operation is taking place via the internet only. The internet is filled with several hackers and attackers that causes vulnerability to the devices available on the internet [17]. In the same sense this model will also be vulnerable to the attacks. Hence, the chance of data breach, malicious attacks to the systems are always possible to occur.

\subsubsection{Management of Huge Data}

The system has several number of sensors and RFID tags, the function of these devices is to collect all the possible data in its surrounding. Thus, a huge amount of data is generated at a greater level. The management as well as analysis of the data are a huge concern for the management team of the system [2]. The possibility of data loss or incorrect data occurs due to this problem. This may lead to the incorrect analysis to the data and results will also alter according to those. 


\subsubsection{Privacy Concerns}

The privacy policies of the new technologies are way strict in actual practice. This may become a wall in accepting the model by everyone operating in the system [8]. This model involves the presence of information of the students, instructors and the staffs hence any misplace of the information may lead to the privacy disturbance of the concerned authorities of the details. Hence, many may not agree in adopting the model.

\section{Failure of Software or Hardware}

The model is totally based on the operations of the hardware of the institute and the advanced software for the operation of all the activities. The old versions of software may become hindrance in the proper functionality of the model [18]. The failure of the hardware such as nonfunctionality of the monitor, keyboards, CPU will stop the operations of the model. The disturbance in the institute's network will not let the operation perform as decided. The unavailability of the server which provides power to the system will stop the working of the model.

\subsection{Application of the Model}

The unified architecture of the model enables in providing several application of the physical life of the every individual. This technology is used mainly for enhancing the abilities of the tools for education, provide better experience and obtain most of the usability out of them. Hence, the following applications are:

\subsubsection{Effective Security System}

As the functions of the technology is totally based on the tools that are equipped with all the advanced technologies and the system is totally based on the online platform, the ability to provide secure operation of every activity is possible [21]. The allowance of any tasks with effective encryption and decryption from the sender to the receiver is available. Hence, any transaction containing sensitive data is possible through the system. The system is best for storing the personal details of the students, teachers and the employees of the institute and maintain the credibility of the data as well as the source of their obtaining.

\subsubsection{Voice Recognition}

The sensors and the tags of the IoT devices are have the aim of obtaining the data that is occurring in their surroundings. Along with that the voice of the nearby objects are also getting captured at the same time. Hence, the system allows to convert the captured voice into usable data [28]. The ability of the sensors is utilized and explored well with the presence of the ability of the system to capture the voices and provide the exact output. The advancement of the technology has provided the ability to easily recognize the voices captured from the devices.

\subsubsection{Data Translation}

The techniques of the tools to capture data and analyse them are associated with the advancement of the system proposed. The ability to transform data into understandable state is the speciality of the techniques involved with the proposed system [23]. The translation of the data or the image or the voice captured are possible to obtain is the required for. Hence the proposed system is applicable to the various departments of the institute. 


\subsubsection{Healthcare System}

As seen that the system captures the activities around the sensors and then analyse them to provide meaningful output. The propped system is also applicable to use the system to keep track of all the staffs, students, teacher's details in the aspect of their health. Then the behavioural pattern can be generated out from the details taken of each person [16]. The pattern can be used for predicting the possible health issues and with the proper analysis at the time the solution of the complicate health problems can be solved easily.

\section{FUtURE Directions}

The research presents an initial design of Educational Model IoT-Based to provide the necessary support to both students and staff. Based on the challenges stated in section 3.4, the future focus is to improve the performance of the model in terms of software maintained, management of large volumes of data and lack of technical training. An extended work is expected to be made in that regard to facilitate adopting the proposed model into higher education and move to fully online learning \& management in educational institutions. Case study is to be discussed in the extended version to find the attractive impacts and results on IoT simulation of the proposed model in higher education.

\section{CONClusion}

It can be concluded that the use of IoT for the purpose of combining it in the model for an elearning process or providing a smart class for the students of higher education is proposed well. The main element of the model is the presence of sensors and wearable that collects the data and information from it surrounding and processing it to provide predictive actions. The instructors are highly benefits by this concept as they become more familiar with the students and they are able to provide the exact and direct requirement of the student. The advantages of the model are clearly discussed above and it is expected the challenges can be overcoming in the long run of the processing of the system in the educational system.

\section{REFERENCES}

[1] Ahn, J., Campos, F., Hays, M., \& DiGiacomo, D. (2019). Designing in Context: Reaching beyond Usability in Learning Analytics Dashboard Design. Journal of Learning Analytics, 6(2), 70-85.

[2] Amendola, S., Lodato, R., Manzari, S., Occhiuzzi, C., \&Marrocco, G. (2014). RFID technology for IoT-based personal healthcare in smart spaces. IEEE Internet of things journal, 1(2), 144-152.

[3] Asghar, M. H., Negi, A., \&Mohammadzadeh, N. (2015, May). Principle application and vision in Internet of Things (IoT). In International Conference on Computing, Communication \& Automation (pp. 427-431). IEEE.

[4] Boninger, F., Molnar, A., \&Saldaña, C. M. (2019). Personalized learning and the digital privatization of curriculum and teaching. National Educational Policy Center). Whitepaper accessed at https://nepc. colorado. edu/publication/personalized-learning.

[5] Amasha, M. A., Areed, M. F., Alkhalaf, S., Abougalala, R. A., Elatawy, S. M., \&Khairy, D. (2020, February). The future of using Internet of Things (loTs) and Context-Aware Technology in Elearning. In Proceedings of the 2020 9th International Conference on Educational and Information Technology (pp. 114-123).

[6] Brunner, M., Keller, U., Wenger, M., Fischbach, A., \&Lüdtke, O. (2018). Between-school variation in students' achievement, motivation, affect, and learning strategies: Results from 81 countries for planning group-randomized trials in education. Journal of Research on Educational Effectiveness, $11(3), 452-478$.

[7] $\mathrm{Da} \mathrm{Xu}, \mathrm{L} ., \mathrm{He}, \mathrm{W} .$, \& Li, S. (2014). Internet of things in industries: A survey. IEEE Transactions on industrial informatics, 10(4), 2233-2243. 
[8] Duroc, Y., \& Vera, G. A. (2014). Towards autonomous wireless sensors: RFID and energy harvesting solutions. In Internet of Things (pp. 233-255). Springer, Cham.

[9] Gunawardena, A. (2017). Brief Survey of Analytics in K12 and Higher Education. International Journal on Innovations in Online Education, 1(1).

[10] Halliday, J., \& Anderson, M. (2016). Developing a framework for the visualisation of learning analytics in UK higher education. In Developing effective educational experiences through learning analytics (pp. 119-142). IGI Global.

[11] Bayani, M. (2020, March). The Influence of IoT simulation in the Learning process: A Case study. In Proceedings of the 2020 8th International Conference on Information and Education Technology (pp. 104-109).

[12] Husamuddin, M., \& Qayyum, M. (2017, March). Internet of Things: A study on security and privacy threats. In 2017 2nd International Conference on Anti-Cyber Crimes (ICACC) (pp. 93-97). IEEE.

[13] Jang, Y., Kim, J., \& Lee, W. (2018). Development and application of internet of things educational tool based on peer to peer network. Peer-to-Peer Networking and Applications, 11(6), 1217-1229.

[14] Joksimović, S., Kovanović, V., \& Dawson, S. (2019). The journey of learning analytics. HERDSA Review of Higher Education, 6, 27-63.

[15] Khan, B. H., Corbeil, J. R., \&Corbeil, M. E. (Eds.). (2018). Responsible analytics and data mining in education: Global perspectives on quality, support, and decision making. Routledge.

[16] Khan, M. S., Islam, M. S., \& Deng, H. (2014). Design of a reconfigurable RFID sensing tag as a generic sensing platform toward the future Internet of Things. IEEE Internet of things journal, 1(4), 300-310.

[17] Lee, I., \& Lee, K. (2015). The Internet of Things (IoT): Applications, investments, and challenges for enterprises. Business Horizons, 58(4), 431-440.

[18] Li, S., Da Xu, L., \& Zhao, S. (2015). The internet of things: a survey. Information Systems Frontiers, 17(2), 243-259.

[19] Liu, M., Zou, W., Li, C., Shi, Y., Pan, Z., \& Pan, X. (2019). Using learning analytics to examine relationships between learners' usage data with their profiles and perceptions: A case study of a MOOC designed for working professionals. In Utilizing learning analytics to support study success (pp. 275-294). Springer, Cham.

[20] Loeb, S., \& Byun, E. (2019). Testing, accountability, and school improvement. The ANNALS of the American Academy of Political and Social Science, 683(1), 94-109.

[21] Madakam, S., Lake, V., Lake, V., \& Lake, V. (2015). Internet of Things (IoT): A literature review. Journal of Computer and Communications, 3(05), 164.

[22] Maksimović, M. (2018). IOT concept application in educational sector using collaboration. Facta Universitatis, Series: Teaching, Learning and Teacher Education, 1(2), 137-150.

[23] Matharu, G. S., Upadhyay, P., \& Chaudhary, L. (2014, December). The internet of things: Challenges \& security issues. In 2014 International Conference on Emerging Technologies (ICET) (pp. 54-59). IEEE.

[24] Meenakumari, J., \&Kudari, J. M. (2015). Learning Analytics and its challenges in Education Sector a Survey. Int. J. Comput. Appl, 0975-8887.

[25] Miraz, M. H., Ali, M., Excell, P. S., \& Picking, R. (2015, September). A review on Internet of Things (IoT), Internet of everything (IoT) and Internet of nano things (IoNT). In 2015 Internet Technologies and Applications (ITA) (pp. 219-224). IEEE.

[26] Nouby, A., \&Alkhazali, T. (2017). The effect of designing a blended learning environment on achievement and deep learning of graduate students at the Arabian Gulf University. Open Journal of Social Sciences, 5(10), 248-260.

[27] Pak, K., \& Desimone, L. M. (2019). Developing principals' data-driven decision-making capacity: Lessons from one urban district. Phi Delta Kappan, 100(7), 37-42.

[28] Roselli, L., Mariotti, C., Mezzanotte, P., Alimenti, F., Orecchini, G., Virili, M., \& Carvalho, N. B. (2015, January). Review of the present technologies concurrently contributing to the implementation of the Internet of Things (IoT) paradigm: RFID, Green Electronics, WPT and Energy Harvesting. In 2015 IEEE Topical Conference on Wireless Sensors and Sensor Networks (WiSNet) (pp. 1-3). IEEE.

[29] Sarnok, K., \&Wannapiroon, P. (2018). Connectivism learning activity in ubiquitous learning environment by using IoT for digital native. Veridian E-Journal, Silpakorn University (Humanities, Social Sciences and arts), 11(4), 405-418.

[30] Tyler-Wood, T. L., Cockerham, D., \& Johnson, K. R. (2018). Implementing new technologies in a middle school curriculum: a rural perspective. Smart Learning Environments, 5(1), 22. 
[31] Wang, K. H., Chen, C. M., Fang, W., \& Wu, T. Y. (2018). On the security of a new ultra-lightweight authentication protocol in IoT environment for RFID tags. The Journal of Supercomputing, 74(1), 6570.

[32] Wise, A. F. (2019). Learning analytics: Using data-informed decision-making to improve teaching and learning. In Contemporary technologies in education (pp. 119-143). Palgrave Macmillan, Cham.

(C) 2020 By AIRCC Publishing Corporation. This article is published under the Creative Commons Attribution (CC BY) license 